\title{
Diferencial de Renda do Migrante de Retorno Nordestino por Setor de Trabalho
}

\section{Differential Income of the Northeast Return Migrant in Brazil by Work Sector}

\author{
Cícero Francisco de Lima ${ }^{\mathrm{a}}$ \\ Jair Andrade Araújo ${ }^{a}$ \\ Edward Martins Costa ${ }^{a}$
}

\begin{abstract}
Resumo: Este trabalho tem como objetivo analisar o efeito discriminação de rendimentos do trabalho por sexo, cor e situação de domicílio entre os migrantes de retorno nordestino. A análise considera quatro setores de atividade na região Nordeste: setor formal privado, informal privado, público e autônomo informal. Para se realizar a análise do diferencial de rendimentos, utiliza-se o método não paramétrico de Ñopo (2008). Como resultado, o modelo aponta discriminação de rendimentos por sexo em relação às mulheres em todos os setores, exceto no setor público. Ademais, os resultados referentes aos retornados por situação de domicílios são similares ao pareamento por sexo. Em relação à decomposição de rendimento por cor, o efeito discriminação apresenta-se negativo no mercado de trabalho agregado e no setor informal privado.
\end{abstract}

Palavras-chave: Migração de retorno. Mercado de trabalho. Diferencial de rendimento.

\begin{abstract}
This paper analyzes the effect of discrimination of labor income by sex, color and domicile situation among migrants returning from the Northeast in Brazil. The analysis considers four sectors of activity in the Northeast region: formal private sector, informal private sector, public and autonomous informal sector. To perform the yield differential analysis, the non-parametric method of Ñopo (2008) was used. The Nopo model captured income discrimination by sex in relation to women in all sectors, except in the public sector. The results referring to the returnees by household situation were similar to the pairing by sex. In relation to the breakdown of income by race, the discrimination effect was negative in the aggregate labor market and in the private informal sector.
\end{abstract}

Keywords: Return migration. Labor market. Yield differential.

JEL Classification: J61; J71.

1 Introdução

A migração de retorno tem se revelado como fenômeno relevante para a dinâmica da mobilidade de pessoas no país (SILVEIRA NETO; AZZONI, 2008).

Universidade Federal do Ceará (UFC), Departamento de Economia Agrícola. Fortaleza, Ceará, Brasil. 
Segundo Siqueira, Magalhães e Silveira Neto (2006), os dados do censo demográfico de 2000 mostraram que cerca de 1,335 milhões de brasileiros decidiram voltar aos seus estados de naturalidade entre os anos de 1995-2000, representando $22 \%$ de todos os deslocamentos migratórios nesse período. Do total de migrantes de retorno, $40 \%$ tiveram como destino a região Nordeste.

Oliveira e Jannuzzi (2005) explicam que transformações na estrutura produtiva brasileira, aliadas às novas configurações do desenvolvimento regional a partir da década de 70, ambientam importantes modificações na dinâmica migratória nordestina. Nesse sentido, Cunha e Baeninger (2000) destacam que o processo de desconcentração econômica, amparado pelas políticas de incentivo ao investimento industrial no Nordeste, influenciou os fluxos de retorno para essa região a partir década de 1980. Ao longo desses períodos, surgiram novas configurações regionais, consideradas espaços produtivos modernos, relevantes para o retorno de nordestinos, destacando-se o complexo petroquímico de Camaçari (BA), o polo têxtil e de confecções de Fortaleza (CE), o complexo minerometalúrgico de Carajás (MA), o polo agroindustrial de Petrolina (PE)/Juazeiro (BA) e a fruticultura do Rio Grande do Norte (ARAÚJO, 2000).

De acordo com Guimaraes Neto (2012), a partir da primeira metade da década de 1990, a economia nacional - e particularmente a economia nordestina - apresentou relevante ritmo de crescimento econômico. Nesse contexto, o Banco do Nordeste Brasileiro (BNB) apresentou dados de que a região Nordeste cresceu a $4 \%$ ao ano, entre 2001-2010, enquanto que o Brasil cresceu em média 3,7\% nesse mesmo período (BANCO DO NORDESTE BRASILEIRO, 2012). Segundo Guimaraes Neto (2012), esse crescimento, mesmo que moderado, está associado à estabilização dos preços, ao aumento dos investimentos públicos e privados e à ampliação do crédito às empresas e às famílias. De acordo com o autor, esses fatores tendem a refletir em melhorias sobre o mercado de trabalho da região Nordeste. ${ }^{1}$

Lima, Simões e Oliveira (2012) destacam que os deslocamentos de retorno também podem estar positivamente correlacionados às piores condições de vida nos locais de destino do migrante.

Apesar da importância que os fluxos migratórios de retorno representam para o país, conforme Ramalho e Silveira Neto (2009), ainda há poucas pesquisas sobre a relação desses indivíduos com o mercado de trabalho das regiões de origem dos indivíduos, sendo relevante aprofundar essa temática.

Logo, este trabalho tem como objetivo verificar se existe discriminação de renda do trabalho por sexo, cor e situação de domicílio entre o migrante de re-

1 Segundo os Microdados do Censo Demográfico de 2010 (IBGE, 2010), os estados nordestinos que mais atraíram migrantes de retorno foram primeiramente Bahia, em seguida Ceará, Maranhão e Pernambuco (LIMA; JUSTO, 2014). 
torno nordestino no ano de 2010. A análise leva em consideração os setores de trabalhos (formal e informal), em que o indivíduo retornado foi inserido.

Busca-se contribuir com a literatura nacional, uma vez que se verifica o diferencial de rendimentos sobre um grupo exclusivo de trabalhadores, o migrante de retorno nordestino, considerando-se os setores de trabalhos desses indivíduos. De acordo com Mariano, Costa, Guimarães e Souza (2018), dependendo do setor de trabalho, a discriminação de rendimentos pode ter efeitos diferenciados.

Além desta introdução, esta pesquisa se divide em mais quatro seções: a segunda apresentada a revisão de literatura; a terceira explana a metodologia; a quarta explica os resultados e realiza as discussões; e, por fim, a quinta traça as considerações finais.

\section{Revisão de Literatura}

Esta seção traz dois subitens: o primeiro reporta-se à relevância da migração de retorno do ponto de vista econômico, no qual enfatizou-se a importância da região Nordeste nos fluxos migratórios de retorno nas últimas décadas. Já o segundo item enfatizou as principais teorias sobre diferencias de salários, destacando evidências empíricas para o caso brasileiro.

\subsection{Aspectos Conceituais da Migração de Retorno e Evidências para o Nordeste Brasileiro}

Segundo Siqueira, Magalhães e Silveira Neto (2006), migração de retorno pode ser definida como quando uma pessoa deixa o seu estado natal, reside algum tempo em outro estado e, depois de determinado período, regressa ao seu lugar de nascimento.

O retorno de pessoas às suas origens é um processo que pode ser considerado como uma ocorrência de caráter, planejada ou não. Na primeira situação, parte do pressuposto de que o migrante obteve sucesso. A opção migrar como investimento superou as expectativas desejadas e o migrante realiza o retorno de forma programada. Já na segunda situação, o retorno é consequência do insucesso do migrante no local de destino, devido, principalmente, à falta de emprego e outros objetivos não alcançados. Diante dessa situação, o retorno pode representar alternativa com menor custo que se deslocar a um terceiro destino (SIQUEIRA; MAGALHÃES; SILVEIRA NETO, 2008).

Segundo Dustmann e Kirchkamp (2002), a migração de retorno pode trazer consigo duas consequências básicas para os locais de origem do migrante. Por um lado, pode representar ganhos, partindo-se do pressuposto de que esses indivíduos tenham desenvolvido novos conhecimentos, resultando em uma maior qualifica- 
ção da mão de obra. Além do mais, eles podem trazer consigo recursos, o que possibilitaria realizar novos investimentos em seus locais de retornos. Entretanto, do ponto de vista econômico, o migrante de retorno pode representar também um problema, tendo em vista o fato de ser uma pessoa mais velha, desmotivada, desempregada ou com baixa contribuição para o mercado de trabalho.

Segundo Siqueira, Magalhães e Silveira Neto (2006), nas últimas décadas os movimentos migratórios de retorno passaram a merecer importância no estudo da migração brasileira. Lima, Simões e Oliveira (2012), ao analisarem a caracterização dos padrões migratórios brasileiros no período 1980-2010, verificam que os movimentos migratórios de retornos cresceram de, aproximadamente, $12 \%$, em 1980, para 18,8\%, em 2010.

Nesse processo de retorno, ganham destaque os estados da região Nordeste, visto que, em períodos anteriores, representavam as unidades da federação que mais enviaram migrantes para outras regiões do país. A partir de então, começou a ser notável o fluxo migratório inverso, ou seja, a volta de pessoas a seus locais de origem (SIQUEIRA; MAGALHÃES; SILVEIRA NETO, 2006). Cunha (2000), em uma perspectiva otimista, relaciona os movimentos de retorno a uma manifestação de sinais positivos na economia do Nordeste, visto que essa região apresentou uma administração pública mais eficaz e foram criadas novas fontes de trabalho.

Cunha (2006), ao estudar a situação migratória brasileira nos primeiros anos do século XXI, identifica que cerca de $30 \%$ dos movimentos migratórios registrados no país, entre 1999 e 2004, são de migração de retorno, enquanto que, considerando apenas a região Nordeste, esse percentual chega a 51\%. De forma complementar a essa análise, Siqueira, Magalhães e Silveira Neto (2008) identificam que o migrante de retorno brasileiro é composto basicamente por pessoas jovens ou adultas e com maiores chances de estarem desocupadas ou de serem trabalhadores sem carteira de trabalho assinada. Esse resultado se agrava ao se tratar das regiões pobres, especialmente o Nordeste, tendo em vista que essas pessoas tendem a ser menos escolarizadas.

Ramalho e Silveira Neto (2009) analisam a inserção produtiva do migrante de retorno no mercado de trabalho brasileiro, tendo como base a PNAD de 2007. Considerando um modelo de múltipla escolha ocupacional, os autores observam que a probabilidade de emprego do migrante de retorno no setor formal é positivamente correlacionada ao grau de instrução. Essa correlação é maior ainda quando se considera o ingresso no setor público. Notam, também, que os migrantes de retorno do sexo feminino, de baixa escolaridade ou que não chefiam a família têm maiores probabilidades de serem absorvidos nos setores informais da economia.

Dessa forma, observa-se que o processo migratório é visto como um importante componente de mudança demográfica. Cada movimento migratório pode 
assumir diferentes significados, entretanto, em geral, representa o nível de crescimento e desenvolvimento em que se encontram as regiões. A migração funciona como sinalizador do nível de distribuição espacial dos recursos.

\subsection{Diferencial de Renda e Evidências Empíricas no Mercado de Trabalho Brasileiro}

As diferenças de rendimentos proveniente do trabalho são explicadas por diversas teorias econômicas na literatura, tais como a teoria do capital humano, a teoria de diferenciais de salários compensatórios e a teoria da discriminação salarial.

A teoria do capital humano explica que trabalhadores com maiores níveis de escolaridade e experiência tendem a ser melhor remunerados. Nesse mesmo raciocínio, a teoria das habilidades não mensuradas argumenta que a influência do talento individual do trabalhador o torna mais produtivo, eficiente e, consequentemente, é compensado com um salário mais elevado (FERNANDES, 2002). Já a teoria de diferenciais de salários compensatórios considera que alguns trabalhadores são melhor remunerados por exercerem atividade laborais arriscadas (ALMEIDA; ARAÚJO JÚNIOR, 2017).

A teoria da discriminação econômica, segundo Fernandes (2002), explica a existência de diferença salarial como resultado da discriminação, visto que alguns grupos de indivíduos, tais como mulheres e negros, recebem salários inferiores, mesmo com características como escolaridade, eficiência, jornada de trabalho equivalentes às características dos trabalhadores mais remunerados.

Dessa forma, segundo o autor, as diferenças de rendimentos podem ocorrer tanto devido ao efeito de características observáveis do indivíduo, condições de trabalho, assim como também devido ao efeito discriminatório, pelo fato de ser mulher, não branco ou qualquer outra condição que não tenha influência sobre a produtividade no trabalho.

Existe uma importante discussão acadêmica, no Brasil, sobre o diferencial de renda em decorrência do fator discriminação. Mesmo com o aumento do nível de escolaridade e maior participação no mercado de trabalho, as mulheres e os indivíduos de cor não branca ainda apresentam notável discriminação salarial em relação aos homens e pessoas de cor branca. Vários estudos mostram esse diferencial de renda no mercado de trabalho brasileiro, dentre eles pode-se destacar os trabalhos comentados a seguir.

Abramo (2006), ao analisar as desigualdades de gênero e cor no mercado de trabalho brasileiro, identifica que as mulheres recebem, em média, 79\% da remuneração média dos homens por hora trabalhada e que os trabalhadores negros de ambos os sexos recebem, em média, a metade do que recebem os trabalhadores brancos de ambos os sexos. Já as mulheres negras recebem apenas 39\% do que recebem os homens brancos. 
Mattos e Machado (2006) analisam o diferencial de rendimento por cor de pele no Brasil entre 1987 e 2001. Os autores utilizam o método de Oaxaca-Blinder e consideram quatro grupos homogêneos (homens brancos, homens negros, mulheres brancas e mulheres negras). Como resultado, observaram a presença de discriminação por sexo e cor no país em relação à mulher e aos negros ao longo do período analisado. Além disso, identificaram que a taxa de desemprego no caso brasileiro é maior para o grupo de homens negros e o das mulheres negras, quando comparados aos grupos dos homens brancos e das mulheres brancas.

Na mesma perspectiva, Moraes (2005) verifica o grau de discriminação salarial por gênero nos segmentos industriais no país adotando o método de Horrace e Oaxaca. Os resultados mostraram que, em média, as mulheres são mais escolarizadas que os homens, entretanto, seu tempo médio de trabalho nas empresas é inferior. As mulheres estão predominantemente empregadas nos segmentos das indústrias tradicionais, indústria de vestuário e indústria calçadista. Na maior parte dos setores, a média salarial das mulheres é menor que a média de salário dos homens, sendo que parte dessa diferença de rendimento ocorreu devido à discriminação.

Machado, Oliveira e Antigo (2008) investigam a evolução do diferencial de rendimentos no Brasil no setor formal e informal no período de 1992, 1998 e 2004. Os resultados obtidos mostram que os ocupados do setor informal, especialmente no qual são considerados os trabalhadores por conta própria, obtiveram rendimentos mais elevados por suas características não observáveis, sendo que essa tendência mostrou-se crescente no período analisado.

Pereira e Oliveira (2016) estudam os diferenciais de rendimento por gênero no Rio Grande do Sul, com base nos Microdados do Censo de 2010 (IBGE, 2010). Observaram que a educação tem papel fundamental na determinação dos rendimentos dos trabalhadores. Verificaram que a desagregação da variável escolaridade permite identificar os retornos nos rendimentos gerados em relação a cada nível de qualificação educacional. Ao fazerem a decomposição do diferencial de rendimento, constataram que existe discriminação estatística quanto às mulheres no estado, apesar de ser em uma proporção menor do que é encontrado em outros trabalhos.

Já Bartalotti e Leme (2007) analisam a discriminação salarial aplicando uma abordagem por decomposição contrafatual com regressões quantílicas. Afirmam que a desigualdade salarial, principalmente a resultante da discriminação contra negros e mulheres no mercado de trabalho brasileiro, é um fator importante no processo de concentração de renda do país. Os dados obtidos pelos autores mostraram que a discriminação afeta principalmente as mulheres negras, seguidas das mulheres brancas e dos homens negros. O retorno da educação para os negros de ambos os gêneros é inferior ao dos brancos para todos os quantis estimados, sendo 
que os homens negros sofrem discriminação crescente, conforme avançam para estratos mais elevados de renda.

Nessa mesma finalidade, Mariano, Costa, Guimarães e Souza (2018) observam os diferenciais de rendimentos entre cores e gêneros nas regiões metropolitanas brasileiras utilizando dados da PNAD (IBGE, 2014). Estratificaram a análise em quatro níveis ocupacionais: todas as ocupações, dirigentes, técnicos e serviços. Os resultados apresentados mostraram que as mulheres, assim como os indivíduos não brancos, têm as piores remunerações em todas as regiões metropolitanas e nos quatros níveis ocupacionais, sendo que a categoria dos dirigentes apresentou a maior diferença salarial, tanto por gênero, quanto por cor. Ainda segundo os autores, os dados obtidos por meio do método de Oaxaca-Blinder comparados aos dados apresentados pelo método não paramétrico de Nopo (2008) tendem a subestimar os resultados da análise.

Segundo Abramo (2006), as desigualdades de gênero e cor no Brasil são eixos estruturais no processo de desigualdade social no país, sendo responsável pela permanência e reprodução das situações de pobreza e exclusão social. Estudos precisos e análises da evolução desses indicadores no mercado de trabalho são condições indispensáveis para a elaboração de políticas voltadas para esse problema.

Apesar da existencia de vários trabalhos na literatura brasileira que abordam empiricamente a discriminação de rendimenos, estudos que relacionam essa temática aos fluxos migratórios não foram encontrados. Com base nisso, este trabalho se propõe a verificar a existência de descriminação de rendimentos nos setores formais e informais nordestino, especificamente sobre o trabalhador que retornou das demais regiões do país para o Nordeste.

\section{Metodologia}

Apresenta-se nesta seção a base de dados utilizada neste trabalho, bem como as definições das variáveis e os filtros aplicados ao banco de dados. Por fim, foi apresentada a metodologia usada para atingir os objetivos.

\subsection{Base de Dados e Descrição das Variáveis}

O presente trabalho utiliza microdados extraídos dos Microdados do Censo Demográfico de 2010 (IBGE, 2010). Devido a algumas restrições de pesquisa, diversos filtros foram realizados na utilização dos dados visando deixar a amostra mais homogênea. Desse modo, foram excluídas da amostra pessoas com idade menor que 18 anos e maior que 65 anos. Esse é um procedimento comum na literatura, conforme sugere Justo e Silveira Neto (2007), tendo em vista que as pessoas per- 
tencentes a esses dois grupos extremos têm mais probabilidade de estar fora do mercado de trabalho. Foram excluídas também da amostra pessoas com renda superior a $\mathrm{R} \$ 500.000,00$.

$\mathrm{Na}$ criação da variável de migração (migrante de retorno nordestino), foi considerado o critério de data fixa, ou seja, pessoas que nasceram em alguma unidade da federação do Nordeste, em 2010 (data da entrevista), estavam na unidade da federação de nascimento e, em 2005 (cinco anos atrás), estavam em alguma unidade da federação fora da região Nordeste.

Para caracterizar o mercado de trabalho como setor formal e setor informal, foi utilizada a variável "neste trabalho era" disponibilizada no censo demográfico. Optou-se por dividir o setor de ocupação formal em mais dois subgrupos: a) trabalhadores empregados no setor formal-privado; e b) trabalhadores do setor formal-público. O setor informal foi também dividido em mais dois subgrupos: c) ocupados no setor informal-assalariado; e d) trabalhadores do setor informal-autônomo. A divisão do mercado de trabalho em quatro subgrupos foi feita com base em Santos e Ramalho (2011).

O grupo $a$ é composto pelo total de empregados com carteira de trabalho assinada, trabalhadores por conta própria que contribuíam para a previdência social e empregadores que contribuíam para a previdência social. Os trabalhadores do setor formal-público, grupo $b$, correspondem aos empregados pelo regime jurídico dos funcionários públicos. O grupo c corresponde aos empregados sem carteira de trabalho assinada. O grupo $d$ é formado por trabalhadores por conta própria que não contribuíam para a previdência social e por empregadores que não contribuím para a previdência social.

Segundo Santos e Ramalho (2011), a divisão do setor formal e informal em subgrupos é bastante significativa, então algumas hipóteses nesse agrupamento podem ser assumidas: a inserção de trabalhadores no setor informal pode requerer habilidades específicas, a depender do tipo de ocupação; para pessoas que trabalham por conta própria, por exemplo, o alto nível de educação parece não ser determinante, entretanto outras habilidades podem ser demandadas no mercado informal. Outra informação importante é que a não contribuição para a previdência social é uma característica significante do trabalho informal. Já aqueles que trabalham no setor público tende a ter elevado nível de escolaridade.

Cabe ressaltar que os Microdados do Censo Demográfico de 2010 (IBGE, 2010) não disponibiliza a variável "anos de estudos", então o objetivo deste trabalho foi criar uma proxy para medir os anos de escolaridade do migrante de retorno. Na construção dessa variável, foram combinadas informações referentes a "sabe ler e escrever", "curso mais elevado que frequentou" e "conclusão desse curso", de acordo com o censo demográfico. Conforme sugerem Thomas, Wang e Fan 
(2000), foi atribuído anos de estudos ${ }^{2}$ conforme o nível de escolaridade do indivíduo. As variáveis ${ }^{3}$ utilizadas para explicar as diferenças de rendimentos foram selecionadas seguindo-se a teoria do capital humano, conforme o Quadro 1.

Quadro 1 - Definições das variáveis utilizadas

\begin{tabular}{|c|c|}
\hline Variável dependente & Descrição \\
\hline Ln rendimento ${ }^{1}$ & $\begin{array}{l}\text { Logaritmo natural do rendimento do trabalho } \\
\text { principal }\end{array}$ \\
\hline Variáveis explicativas & Descrição \\
\hline Educação & Anos de estudos \\
\hline Horas trabalhadas & $\begin{array}{l}\text { Quantidade de horas trabalhadas semanal- } \\
\text { mente }\end{array}$ \\
\hline Exper. & $\begin{array}{l}\text { Experiência }{ }^{2}=(\text { idade } \text { - anos de estudo - } 6 \\
\text { anos) }\end{array}$ \\
\hline Exper.2 & Experiência ao quadrado \\
\hline Dummy sexo & Masculino $=1$ e Feminino $=0$ \\
\hline Dummy cor $^{3}$ & Branco $=1$ e Não branco $=0$ \\
\hline Dummy situação de domicílio & Urbano $=1$ e Rural $=0$ \\
\hline
\end{tabular}

Fonte: Elaboração própria.

Cabe destacar que considerar custo de vida por região brasileira, assim como características de emprego e mercado de trabalho regional seriam importantes na análise da discriminação de rendimentos, no entanto, por limitações de dados, esses procedimentos não foram utilizados neste trabalho.

\subsection{Modelo Econométrico}

Para se mensurar o efeito discriminação por sexo, cor e situação de domicílio em relação ao rendimento do trabalho do migrante de retorno nordestino, foi realizado o pareamento de semelhantes por meio do método não paramétrico de Ñopo (2008). De acordo com Ñopo (2008), Brito e Waltenberg (2014) e Mariano, Costa, Guimarães e Souza (2018), esse método apresenta vantagens quando comparado a outros modelos que verificam diferenciais de rendimentos. Segundo esses autores, o modelo Oaxaca-Blinder (1973), por exemplo, é um dos mais utili-

$2 \quad$ Para mais detalhes técnicos, ver Thomas, Wang, Fan (2000).

3 Equação de rendimento para sexo $=$ anos de estudos + horas trabalhadas + experiência + experiência ${ }^{2}+$ cor + situação de domicílio, quando migrante de retorno mulher. Equação de rendimento para cor $=$ anos de estudos + horas trabalhadas + experiência + experiência $^{2}+$ sexo + situação de domicílio, quando migrante de retorno não branco. Equação de rendimento para situação de domicílio $=$ anos de educação + horas trabalhadas + experiência + experiência ${ }^{2}+$ sexo, quando migrante de retorno rural. 
zados na literatura, entretanto tende a superestimar os efeitos da decomposição de rendimentos devido a um problema de má especificação ao considerar as equações de rendimentos fora do "suporte comum" 4 em relação às características dos indivíduos. Dessa forma, os efeitos apresentados por meio da decomposição de Ñopo são mais robustos, justificando-se o uso desse método.

\subsubsection{Decomposição de Ñopo}

O modelo não paramétrico de Ñopo (2008) utiliza técnicas de pareamentos de semelhantes com a finalidade de explicar os diferenciais de rendimentos por grupo (sexo, cor) de pessoas. Esse diferencial é calculado em função do valor esperado dos rendimentos atribuídos às características observáveis dos indivíduos e de uma função de distribuição acumulada dessas características. Esse modelo se mostra como sendo uma alternativa à decomposição de Oaxaca-Blinder (1973), considerando-se que esse modelo superestima o componente "gap" atribuído às diferenças de rendimentos.

De acordo com Nõpo (2008), considera-se Y a variável aleatória que modela os rendimentos dos indivíduos, enquanto que a variável $X$ é um vetor de características para cada pessoa (tais como, idade, educação, experiência, estado civil, entre outros), relacionado ao ganho individual. $\mathrm{F}^{\mathrm{M}}\left(\right.$.) e $\mathrm{F}^{\mathrm{F}}($.), são as funções de distribuição acumulada condicional, visto que o indivíduo é dos sexos masculino e feminino, respectivamente, e $\mathrm{dF}^{\mathrm{M}}$ (.) e $\mathrm{dF}^{\mathrm{F}}$ (.) são as respectivas medidas de probabilidades.

Dessa forma, tem-se que o valor esperado dos rendimentos, condicionado às características e ao "gênero" (sexo) é representado por g⿳⿲丶丶㇒一八 $($.) e gF (.), ou seja, por meio das seguintes equações:

$$
\begin{aligned}
& E[Y \mid M]=\int_{S^{M}} g^{M}(x) d F^{M}(x) \\
& E[Y \mid F]=\int_{S^{F}}^{F} g^{F}(x) d F^{F}(x)
\end{aligned}
$$

Nass equações 1 e 2, $S^{\mathrm{M}}$ e $\mathrm{S}^{\mathrm{F}}$ representam o suporte de distribuição de características/atributos para homens e mulheres, respectivamente. Assim, o diferencial entre os rendimentos pode ser definido por:

$$
\begin{gathered}
\Delta=\mathrm{E}[\mathrm{Y} \mid \mathrm{M}]-\mathrm{E}[\mathrm{Y} \mid \mathrm{F}] \\
\Delta=\int_{\mathrm{S}^{\mathrm{M}}}^{\mathrm{M}} \mathrm{g}^{\mathrm{M}}(\mathrm{x}) \mathrm{dF}^{\mathrm{M}}(\mathrm{x})-\int_{\mathrm{S}^{\mathrm{F}}}^{\mathrm{F}} \mathrm{g}^{\mathrm{F}}(\mathrm{x}) \mathrm{dF}^{\mathrm{F}}(\mathrm{x})
\end{gathered}
$$

4 De acordo com Nopo (2008), o termo "suporte comum" significa grupo de indivíduos com características similares. 
O suporte da distribuição de características para as mulheres, $\mathrm{S}^{\mathrm{F}}$ e o suporte de distribuição para os homens, $\mathrm{S}^{\mathrm{M}}$, são diferentes. Assim, cada integral obtida na equação 4 pode de ser decomposta em dois termos, dentro e fora do suporte comum. Nesse sentido, o diferencial total é decomposto em quatro componentes, considerando-se as diferenças salariais por gênero e fora do suporte comum. $\mathrm{O}$ diferencial e a decomposição em partes podem ser observados na seguinte equação:

$$
\Delta=\Delta_{\mathrm{M}}+\Delta_{\mathrm{X}}+\Delta_{0}+\Delta_{\mathrm{F}}
$$

na qual:

$\Delta_{\mathrm{M}}=$ parte do diferencial de rendimentos, que pode ser explicada por características diferentes entre dois grupos de homens. Um desses grupos possui características que podem ser pareadas com as características das mulheres, porém o outro grupo de homens não pode. Caso não houvesse homens não pareados com mulheres, esse componente seria zero;

$\Delta_{\mathrm{X}}=$ parte do diferencial explicada pelo conjunto de características entre homens e mulheres que se encontram dentro do suporte comum;

$\Delta_{0}=$ parte não explicada do modelo e que tem a função de captar o efeito discriminação da equação;

$\Delta_{\mathrm{F}}=$ tem interpretação semelhante ao termo, entretanto refere-se às mulheres.

Os componentes , segundo Ñopo (2008), captam a existência de diferenças nas características observáveis dos indivíduos analisados. Já o termo corresponde a diferenças de características que não podem ser observadas, como gênero e cor. $\mathrm{O}$ efeito total das diferenças de rendimentos entre os indivíduos pode ser representado na seguinte equação:

$$
\Delta=\left(\Delta_{\mathrm{M}}+\Delta_{\mathrm{X}}+\Delta_{\mathrm{F}}\right)+\Delta_{0}
$$

Cabe destacar que, nos resultados (apresentados na Tabela 3, disposta na seção 4.2 mais adiante), os componentes dos diferenciais de rendimentos foram definidos da seguinte maneira: $\mathrm{D}=$ diferencial total; $\mathrm{D} 0$ = efeito das características não observáveis; e DM (DB, DU) + DF (DBN, DR) + DX = efeito das características observáveis.

Logo, DM corresponde à parte do diferencial de rendimentos que pode ser explicada por características diferentes entre dois grupos de homens. DB e DU têm interpretação semelhante ao termo DM, no entanto se referem aos brancos e urbanos, respectivamente. Os termos DF, DNB e DR se referem ao sexo feminino, não brancos e residentes em áreas rurais, respectivamente, e também seguem a mesma interpretação do termo DM. 
DX é o diferencial de renda explicada pelas características observáveis entre homens e mulheres (branco e não branco; urbano e rural) dentro do suporte comum. Quanto mais próximo de zero forem os valores do termo DX, mais robusto será o pareamento dentro do suporte comum entre as pessoas.

A realização do pareamento de Ñopo (2008) segue um procedimento técnico que pode ser resumido em alguns passos:

a) primeiro passo: seleciona-se uma mulher da amostra sem reposição;

b) segundo passo: selecionam-se todos os homens que tenham características observáveis $(\mathrm{X})$ semelhantes às mulheres selecionadas no primeiro passo;

c) terceiro passo: com os indivíduos selecionados no segundo passo, constrói-se um "indivíduo sintético", cujo rendimento é a média de todos eles, e combina-se com a mulher do primeiro passo;

d) quarto passo: inserem-se as observações de mulheres e homens sintéticos em uma nova mostra de indivíduos pareados;

e) quinto passo: repetem-se os passos primeiro a quarto até esgotar-se a amostra original de mulheres.

Essa demonstração apresentada sobre as equações dos diferenciais de rendimentos esperados condicionados ao sexo (mulher e homem) é aplicada de forma análoga para se encontrar as equações dos diferenciais de rendimentos esperados condicionados à variável cor (não branco e branco) e as equações dos diferenciais de rendimentos condicionados à situação de domicílio do migrante de retorno (rural ou urbano). Cabe ressaltar que, independentemente do sexo, cor, situação de domicílio ou qualquer outra característica que não afeta a produtividade do trabalho, era de se esperar que pessoas com características similares tivessem remunerações iguais, isso implicaria $\Delta_{0}=0$, ou seja, não existiria discriminação salarial.

\section{Resultados e Discussão}

Esta seção está dividida em dois tópicos. Na primeira parte, foram realizadas análises estatísticas das variáveis, buscando evidências sobre o diferencial de rendimentos entre os grupos de trabalhadores analisados. Em seguida, foram apresentados os resultados estimados pelo método econométrico.

\subsection{Estatísticas Descritivas}

A análise descritiva das variáveis realiza uma verificação prévia do diferencial de rendimento sobre o migrante de retorno nordestino. A Tabela 1 mostra informações relativas às variáveis níveis de instrução (em anos de estudos), horas trabalhadas semanalmente e nível de renda mensal decorrente do trabalho princi- 
pal. ${ }^{5}$ Os dados cruzam informações por setor de trabalho, ${ }^{6}$ buscando evidenciar o efeito discriminação por sexo, cor e situação de domicílio do migrante de retorno. Considerando-se a análise por sexo, percebe-se que as mulheres possuem maiores anos de estudos do que os homens, exceto no setor público, em que as mulheres e os homens têm a mesma média de escolaridade: 13 anos de estudos. As mulheres demonstram menor nível de escolaridade no setor autônomo informal, ao passo que, em relação aos homens, os menores anos de estudos ocorreram no setor autônomo informal e no setor informal privado.

Observa-se que os indivíduos do sexo masculino trabalharam, em média, mais horas semanalmente que as mulheres, independentemente do setor de trabalho. A maior quantidade de horas trabalhadas pelos homens ocorreram no setor formal privado, 44 horas semanalmente, e as menores horas trabalhadas ocorreram no setor público, 40 horas. Para as mulheres, a análise é similar às informações referente aos homens, ou seja, elas também dedicaram menos tempo de trabalho no setor público e maior tempo trabalhado no setor formal privado.

5 Foram realizados testes de comparação de médias das variáveis anos de estudos, horas trabalhadas e rendimentos entre homens e mulheres, pessoas de cor branca e não branca e entre o trabalhador urbano e o trabalhador rural. Foi usado o t-test e a hipótese nula é que as médias entre os grupos de pessoas são iguais.

6 Outras informações relevantes podem ser consultadas nas tabelas no Apêndice A: a Tabela 4 mostra a distribuição percentual de migrantes de retorno por setor de atividade na região Nordeste; da análise dos dados, nota-se que o percentual de retornados por setor foi predominantemente de homens (exceto no setor público), de cor branca e que retornaram para o meio urbano; a Tabela 5 apresenta informações médias (sobre o migrante de retorno nordestino), por setor de trabalho, referente às variáveis idade, anos de estudos, renda do trabalho principal e horas trabalhadas semanalmente. 
Tabela 1 - Características do migrante de retorno nordestino por setor de trabalho: análise por sexo, cor e situação de domicílio

\begin{tabular}{|c|c|c|c|c|c|c|}
\hline Variável & \multicolumn{2}{|l|}{ Setor formal } & $\begin{array}{l}\text { Setor } \\
\text { formal } \\
\text { privado }\end{array}$ & $\begin{array}{l}\text { Desvio } \\
\text { padrão }\end{array}$ & $\begin{array}{l}\text { Setor } \\
\text { público }\end{array}$ & $\begin{array}{l}\text { Desvio } \\
\text { padrão }\end{array}$ \\
\hline \multirow{13}{*}{ Sexo } & Homem & Anos de estudos & $8^{* * * *}$ & 3,82 & 13 & 3,95 \\
\hline & Mulher & Anos de estudos & 10 & 3,61 & 13 & 3,46 \\
\hline & Homem & Horas trabalhadas & $44^{* * *}$ & 15,30 & $40 * * *$ & 16,22 \\
\hline & Mulher & Horas trabalhadas & 42 & 13,97 & 34 & 10,32 \\
\hline & Homem & Renda mensal & $1487,15 * *$ & 2374,33 & $4679,31 * * *$ & 4986,94 \\
\hline & Mulher & Renda mensal & 1154,78 & 1733,68 & 2678,46 & 3361,92 \\
\hline & \multicolumn{2}{|c|}{ Setor informal } & $\begin{array}{l}\text { Setor } \\
\text { informal } \\
\text { privado }\end{array}$ & $\begin{array}{l}\text { Desvio } \\
\text { padrão }\end{array}$ & $\begin{array}{l}\text { Setor au- } \\
\text { tônomo } \\
\text { informal }\end{array}$ & $\begin{array}{l}\text { Desvio } \\
\text { padrão }\end{array}$ \\
\hline & Homem & Anos de estudos & $7 * * *$ & 3,57 & $7 * *$ & 3,54 \\
\hline & Mulher & Anos de estudos & 9 & 3,69 & 8 & 3,43 \\
\hline & Homem & Horas trabalhadas & $43 * * *$ & 16,48 & $42 * * *$ & 19,56 \\
\hline & Mulher & Horas trabalhadas & 37 & 18,37 & 36 & 20,87 \\
\hline & Homem & Renda mensal & $705,68 * * *$ & 1491,68 & $921,44^{* * *}$ & 2213,96 \\
\hline & Mulher & Renda mensal & 471,57 & 818,11 & 688,36 & 1348,01 \\
\hline Variável & \multicolumn{2}{|c|}{ Setor formal } & $\begin{array}{l}\text { Setor } \\
\text { formal } \\
\text { privado }\end{array}$ & $\begin{array}{l}\text { Desvio } \\
\text { padrão }\end{array}$ & $\begin{array}{l}\text { Setor } \\
\text { público }\end{array}$ & $\begin{array}{l}\text { Desvio } \\
\text { padrão }\end{array}$ \\
\hline \multirow{13}{*}{ Cor } & Branco & Anos de estudos & $9^{* * *}$ & 4,05 & 14 & 3,51 \\
\hline & Não branco & Anos de estudos & 8 & 3,67 & 13 & 3,62 \\
\hline & Branco & Horas trabalhadas & $43^{*}$ & 15,57 & $37^{*}$ & 12,54 \\
\hline & Não branco & Horas trabalhadas & 45 & 14,63 & 36 & 14,11 \\
\hline & Branco & Renda mensal & $1779,24 * * *$ & 2830,33 & $4669,87^{* * *}$ & 5008,95 \\
\hline & Não branco & Renda mensal & 1158,33 & 1701,97 & 2399,55 & 2920,83 \\
\hline & \multicolumn{2}{|c|}{ Setor informal } & $\begin{array}{l}\text { Setor } \\
\text { informal } \\
\text { privado }\end{array}$ & $\begin{array}{l}\text { Desvio } \\
\text { padrão }\end{array}$ & $\begin{array}{l}\text { Setor au- } \\
\text { tônomo } \\
\text { informal }\end{array}$ & $\begin{array}{l}\text { Desvio } \\
\text { padrão }\end{array}$ \\
\hline & Branco & Anos de estudos & $8 * * *$ & 3,72 & $8 * * *$ & 3,67 \\
\hline & Não branco & Anos de estudos & 7 & 3,87 & 7 & 3,49 \\
\hline & Branco & Horas trabalhadas & $41 * *$ & 18,76 & 41 & 20,88 \\
\hline & Não branco & Horas trabalhadas & 40 & 16,98 & 40 & 19,79 \\
\hline & Branco & Renda mensal & $709,40 * * *$ & 1319,98 & $1114,70 * * *$ & 2924,40 \\
\hline & Não branco & Renda mensal & 547,05 & 1193,96 & 700,87 & 1161,05 \\
\hline
\end{tabular}


conclusão.

\begin{tabular}{|c|c|c|c|c|c|c|}
\hline Variável & \multicolumn{2}{|c|}{ Setor formal } & $\begin{array}{l}\text { Setor } \\
\text { formal } \\
\text { privado }\end{array}$ & $\begin{array}{l}\text { Desvio } \\
\text { padrão }\end{array}$ & $\begin{array}{l}\text { Setor } \\
\text { público }\end{array}$ & $\begin{array}{l}\text { Desvio } \\
\text { padrão }\end{array}$ \\
\hline \multirow{13}{*}{$\begin{array}{l}\text { Domicí- } \\
\text { lio }\end{array}$} & Urbano & Anos de estudos & $9 * * *$ & 3,78 & $13 * *$ & 3,63 \\
\hline & Rural & Anos de estudos & 7 & 3,66 & 11 & 3,23 \\
\hline & Urbano & Horas trabalhadas & $44 * * *$ & 14,72 & $37^{*}$ & 13,51 \\
\hline & Rural & Horas trabalhadas & 41 & 17,09 & 30 & 9,53 \\
\hline & Urbano & Renda mensal & $1449,88 * * *$ & 2296,04 & $3699,53^{*}$ & 4288,84 \\
\hline & Rural & Renda mensal & 795,21 & 798,01 & 640,67 & 466,01 \\
\hline & \multicolumn{2}{|c|}{ Setor informal } & $\begin{array}{l}\text { Setor } \\
\text { informal } \\
\text { privado }\end{array}$ & $\begin{array}{l}\text { Desvio } \\
\text { padrão }\end{array}$ & $\begin{array}{l}\text { Setor au- } \\
\text { tônomo } \\
\text { informal }\end{array}$ & $\begin{array}{l}\text { Desvio } \\
\text { padrão }\end{array}$ \\
\hline & Urbano & Anos de estudos & $7 * * *$ & 3,67 & $7 * * *$ & 3,61 \\
\hline & Rural & Anos de estudos & 5 & 3,41 & 6 & 3,16 \\
\hline & Urbano & Horas trabalhadas & $40 * * *$ & 17,73 & $41^{* * *}$ & 20,57 \\
\hline & Não branco & Horas trabalhadas & 38 & 16,66 & 37 & 18,04 \\
\hline & Urbano & Renda mensal & $638,84 * * *$ & 1339,95 & $935,89 * * *$ & 2139,37 \\
\hline & Rural & Renda mensal & 402,29 & 412,01 & 460,76 & 954,22 \\
\hline
\end{tabular}

Fonte: Elaboração própria a partir de IBGE (2010).

Nota: *** significante a $1 \%$; * ${ }^{*}$ significante a $5 \%$; e *significante a $10 \%$.

Os homens são mais bem remunerados do que as mulheres em todos os setores de trabalho. Tanto os homens quanto as mulheres expressaram maior nível de renda nos setores público e formal privado e foram remunerados menos nos setores informal privado e autônomo informal. Apesar de os homens apresentarem maior tempo de horas trabalhadas em relação às mulheres, estas têm maiores anos de estudos. ${ }^{7}$ A diferença salarial por sexo, aqui apresentada, então, pelo menos em parte, pode ser reflexo de um efeito discriminatório.

Considerando-se a análise pelo aspecto cor, verifica-se que pessoas de cor branca têm maiores anos de estudos que as pessoas de cor não branca em todos os setores de atividades. As pessoas do setor público e setor formal privado têm os maiores níveis de escolaridades, respectivamente. Isso ocorre tanto no grupo dos indivíduos de cor branca quanto no grupo de não brancos.

Nota-se que, no setor formal privado e no setor público, as pessoas de cor branca trabalharam mais tempo que os migrantes de retorno de cor não branca. Já nos setores público, informal privado e autônomo informal, os brancos denotaram as maiores horas trabalhadas. Cabe destacar que no setor público, inde-

7 Essas informações estão de acordo com os resultados de Moraes (2005), ao analisar as diferenças salariais nos segmentos industriais no país. 
pendentemente da cor, as pessoas apresentaram as menores horas de trabalho semanalmente.

As pessoas de cor branca foram mais bem remuneradas do que pessoas não brancas. As maiores renumerações, tanto para os homens quanto para as mulheres, ocorreram no setor público. Já as menores remunerações foram observadas no setor informal privado, seguido do setor autônomo informal.

Por situação de domicílio, observa-se que as pessoas que retornaram para o meio urbano, comparadas às que retornaram para o meio rural, apresentaram maiores níveis de escolaridade em todos os setores de trabalho. Os anos de estudos dos indivíduos urbanos e rurais, assim como na análise por sexo e cor, foram maiores no setor público e no setor formal privado. O migrante de retorno urbano trabalhou mais tempo semanalmente do que o migrante de retorno rural.

Em relação ao rendimento médio do trabalho, o migrante de retorno urbano expressou maior remuneração do que o migrante de retorno rural. A princípio, é um resultado esperado, visto que o retornado urbano tem mais anos de estudos e dedica maior tempo de trabalho do que o retornado rural em todos os setores de trabalho. O maior diferencial de renda por domicílio ocorreu nos setores público e formal privado. Parte desse diferencial pode ser explicada por meio de mais anos de estudos e maior número de horas trabalhadas dos trabalhadores urbanos. Assim, também pode ser indício do efeito das características não observáveis, ou seja, descriminação salarial entre os trabalhadores urbanos e rurais.

Com base nesses resultados, a próxima subseção objetiva referenciar maior robustez à análise dos diferenciais de rendimentos, utilizando-se, para isso, o método não paramétrico de Ñopo (2008).

\subsection{Resultados do Pareamento de Ñopo}

Em relação às estimações econométricas, foram usadas equações do diferencial de rendimentos pelo método de Ñopo e de Oaxaca (disponíveis na Tabela 6 do Apêndice A). As estimações obtidas estão de acordo com o esperado, ou seja, a decomposição por Oaxaca tende a superestimar os resultados comparados ao método de Ñopo. Dessa forma, a discussão das estimações é realizada com base apenas em Ñopo (2008).

O pareamento de Nopo mostra o diferencial de rendimentos entre grupos considerando características similares entre os indivíduos, ou seja, dentro do suporte comum. Nesse sentido, a Tabela 2 apresenta os percentuais de pareamentos no mercado de trabalho nordestino em relação ao sexo, cor e domicílio do migrante de retorno. 
Tabela 2 - Percentual de pessoas que retornaram para o Nordeste por sexo, cor e domicílio dentro do suporte comum por setor de atividade

\begin{tabular}{l|c|c|c|c|c}
\hline Variáveis & $\begin{array}{c}\text { Mercado } \\
\text { de trabalho } \\
\text { agregado }\end{array}$ & $\begin{array}{c}\text { Setor for- } \\
\text { mal privado }\end{array}$ & $\begin{array}{c}\text { Setor informal } \\
\text { privado }\end{array}$ & $\begin{array}{c}\text { Setor } \\
\text { público }\end{array}$ & $\begin{array}{c}\text { Setor } \\
\text { autônomo } \\
\text { informal }\end{array}$ \\
\hline Homem & 55,87 & 49,43 & 35,27 & 41,03 & 34,18 \\
Mulher & 45,61 & 32,20 & 37,26 & 33,33 & 23,72 \\
Branco & 49,79 & 39,45 & 31,63 & 34,99 & 29,04 \\
Não branco & 54,74 & 43,06 & 37,81 & 41,72 & 32,35 \\
Urbano & 59,34 & 46,43 & 43,02 & 45,08 & 37,37 \\
Rural & 33,67 & 22,67 & 27,02 & 27,73 & 19,94 \\
\hline
\end{tabular}

Fonte: Elaboração própria a partir de IBGE (2010).

Considerando-se o mercado de trabalho agregado, existe uma quantidade maior de migrante de retorno com características similares em relação a sexo (homem, 55,87\%, e mulher, 45,61\%), cor (branco, 49,79 \%, e não branco, 54,74\%) e domicílio (urbano, 59,34\%, e rural, 33,67\%), quando comparado ao mercado de trabalho separado por setor de atividade.

Por setor de trabalho, os percentuais de participação dentro do suporte comum variam. Em relação ao sexo, esse percentual é maior no grupo dos homens, exceto no setor público. Em relação à cor, o grupo de pessoas brancas, comparado ao não branco, ofereceu menor percentual nos quatros setores de atividades. Em relação ao tipo de domicílio, o grupo dos retornados para o meio rural, dentro do suporte comum, também foi menor, quando comparado ao do meio urbano em todos os setores de trabalho.

A Tabela 3 apresenta o resultado do pareamento de Ñopo, com o objetivo de verificar a existência de diferenciais de rendimentos por sexo, cor e situação de domicílio (rural ou urbano) do migrante de retorno nordestino. Como já mencionado, a análise considera o mercado de trabalho agregado e também é subdividida por setor de trabalho (setor formal privado, setor informal privado, setor público e setor autônomo informal). 
Tabela 3 - Decomposição de Ñopo: sexo, cor e situação de domicílio

\begin{tabular}{|c|c|c|c|c|c|}
\hline \multirow[b]{2}{*}{ Efeitos } & \multicolumn{5}{|c|}{ SEXO } \\
\hline & $\begin{array}{c}\text { Mercado } \\
\text { de trabalho } \\
\text { agregado }\end{array}$ & $\begin{array}{c}\text { Setor } \\
\text { formal } \\
\text { privado }\end{array}$ & $\begin{array}{l}\text { Setor infor- } \\
\text { mal privado }\end{array}$ & $\begin{array}{l}\text { Setor } \\
\text { público }\end{array}$ & $\begin{array}{c}\text { Setor } \\
\text { autônomo } \\
\text { informal }\end{array}$ \\
\hline $\mathrm{D}$ & $-0,0714$ & $-0,0401$ & $-0,0849$ & $-0,0918$ & $-0,0742$ \\
\hline Do & $-0,0834$ & $-0,0448$ & $-0,0719$ & $-0,0793$ & $-0,0745$ \\
\hline $\mathrm{DM}$ & $-0,0073$ & 0,0060 & $-0,0046$ & $-0,0456$ & $-0,0078$ \\
\hline DF & 0,0033 & $-0,0009$ & $-0,0128$ & 0,0323 & $-0,0108$ \\
\hline DX & 0,0160 & $-0,0004$ & 0,0045 & 0,0008 & 0,0189 \\
\hline \multirow{2}{*}{ Observáveis } & 0,01200 & 0,00465 & $-0,01298$ & $-0,01246$ & 0,00029 \\
\hline & $-16,80 \%$ & $-11,60 \%$ & $15,29 \%$ & $13,58 \%$ & $-0,39 \%$ \\
\hline \multirow{2}{*}{ Não observáveis } & $-0,0834$ & $-0,0448$ & $-0,0719$ & $-0,0793$ & $-0,0745$ \\
\hline & $116,80 \%$ & $111,60 \%$ & $84,71 \%$ & $86,42 \%$ & $100,39 \%$ \\
\hline \multicolumn{6}{|c|}{ COR } \\
\hline Efeitos & $\begin{array}{c}\text { Mercado } \\
\text { de trabalho } \\
\text { agregado }\end{array}$ & $\begin{array}{c}\text { Setor } \\
\text { formal } \\
\text { privado }\end{array}$ & $\begin{array}{l}\text { Setor infor- } \\
\text { mal privado }\end{array}$ & $\begin{array}{c}\text { Setor } \\
\text { público }\end{array}$ & $\begin{array}{c}\text { Setor } \\
\text { autônomo } \\
\text { informal }\end{array}$ \\
\hline $\mathrm{D}$ & $-0,0587$ & $-0,0425$ & $-0,0438$ & $-0,1036$ & $-0,0567$ \\
\hline Do & $-0,0408$ & $-0,0315$ & $-0,0262$ & $-0,0879$ & $-0,0314$ \\
\hline $\mathrm{DB}$ & $-0,0118$ & $-0,0020$ & 0,0021 & $-0,0376$ & $-0,0005$ \\
\hline DNB & $-0,0021$ & $-0,0066$ & $-0,0120$ & 0,0174 & $-0,0170$ \\
\hline DX & $-0,0040$ & $-0,0024$ & $-0,0077$ & 0,0045 & $-0,0078$ \\
\hline \multirow{2}{*}{ Observáveis } & $-0,0180$ & $-0,0110$ & $-0,0176$ & $-0,0157$ & $-0,0253$ \\
\hline & $30,57 \%$ & $25,90 \%$ & $40,24 \%$ & $15,14 \%$ & $44,54 \%$ \\
\hline \multirow{2}{*}{ Não observáveis } & $-0,0408$ & $-0,0315$ & $-0,0262$ & $-0,0879$ & $-0,0314$ \\
\hline & $69,43 \%$ & $74,10 \%$ & $59,75 \%$ & $84,86 \%$ & $55,46 \%$ \\
\hline
\end{tabular}


conclusão.

\begin{tabular}{|c|c|c|c|c|c|}
\hline \multicolumn{6}{|c|}{ DOMICÍlLIO } \\
\hline Efeitos & $\begin{array}{c}\text { Mercado } \\
\text { de trabalho } \\
\text { agregado }\end{array}$ & $\begin{array}{c}\text { Setor } \\
\text { formal } \\
\text { privado }\end{array}$ & $\begin{array}{l}\text { Setor infor- } \\
\text { mal privado }\end{array}$ & $\begin{array}{c}\text { Setor } \\
\text { público }\end{array}$ & $\begin{array}{c}\text { Setor } \\
\text { autônomo } \\
\text { informal }\end{array}$ \\
\hline $\mathrm{D}$ & $-0,1177$ & $-0,0698$ & $-0,0701$ & $-0,2098$ & $-0,1367$ \\
\hline Do & $-0,0909$ & $-0,0806$ & $-0,0680$ & $-0,2241$ & $-0,0954$ \\
\hline DU & $-0,0101$ & 0,0041 & $-0,0090$ & $-0,0120$ & $-0,0130$ \\
\hline DR & $-0,0178$ & 0,0011 & $-0,0257$ & 0,0226 & $-0,0408$ \\
\hline DX & 0,0012 & 0,0056 & 0,0326 & 0,0037 & 0,0125 \\
\hline \multirow{2}{*}{ Observáveis } & $-0,0268$ & 0,0108 & $-0,0021$ & 0,0143 & $-0,0413$ \\
\hline & $22,75 \%$ & $-15,51 \%$ & $3,01 \%$ & $-6,81 \%$ & $30,19 \%$ \\
\hline \multirow{2}{*}{ Não observáveis } & $-0,0909$ & $-0,0806$ & $-0,0680$ & $-0,2241$ & $-0,0954$ \\
\hline & $77,25 \%$ & $115,51 \%$ & $96,99 \%$ & $106,81 \%$ & $69,81 \%$ \\
\hline
\end{tabular}

Fonte: Elaboração própria a partir de IBGE (2010).

A estimação pelo método de Ñopo permite obter o diferencial total de rendimentos (D), sendo que parte desse diferencial é explicada pelo efeito das características observáveis e a outra parte, pelas características não observáveis (D0). Nesse sentido, foram estimadas equações de rendimentos para sexo, cor e situação de domicílio, considerando-se o mercado de trabalho agregado e separado por setor de trabalho. Nas equações, foram inseridas as variáveis capital humano: anos de estudos, horas trabalhadas, experiência e experiência ao quadrado. A inserção das equações de rendimento por setor de trabalho permite captar se o trabalhador contribuía ou não para a previdência social e se era pertencente ao mercado de trabalho formal ou informal.

Verificando-se a decomposição de rendimentos por sexo no mercado de trabalho agregado da região Nordeste, observa-se a existência de um diferencial total de renda para o migrante de retorno mulher $(-0,0714)$ em relação ao homem. Cabe destacar que o efeito das características não observáveis $(-0,0834)$ amplia o diferencial de rendimentos, enquanto o efeito das características observáveis tende a reduzir. Esses resultados corroboram a análise apresentada por Mariano, Costa, Guimarães, Souza (2018), referente ao diferencial de rendimento por nível ocupacional no mercado de trabalho das regiões metropolitanas brasileiras. Além disso, nota-se que o componente que representa o diferencial de rendimento dentro dos grupos dos homens (DM), representando aqueles que puderam ser pareados com os que não foram, apresentou efeito negativo sobre os diferenciais nas características observáveis.

Desagregando-se o mercado de trabalho, os dados evidenciam efeitos discriminatórios em relação às mulheres em todos os setores. Os setores público e 
autônomo informal privado expressaram os maiores efeitos das características não observáveis, sendo, respectivamente -0,0793 e -0,0745, enquanto o setor formal privado apresentou o menor efeito. Nota-se, nos setores formal privado e autônomo informal, que os efeitos das características observáveis são positivos, ou seja, agem de modo a reduzir os diferenciais de rendimentos. Esses efeitos, todavia, não foram precisos o suficiente para superar o efeito discriminatório. Em todos os setores, os diferenciais totais de rendimentos em relação às mulheres foram negativos, indicando um gap nos rendimentos nesses setores.

Em relação ao diferencial de rendimento por cor do indivíduo no mercado de trabalho agregado, tanto o efeito discriminatório, quanto o efeito das características observáveis atuam no sentido de aumentar o gap existente entre o migrante de retorno não branco e branco, gerando um efeito total negativo $(-0,0408)$. Verifica-se que o termo DB, que representa o diferencial de rendimento dentro dos grupos dos brancos, o qual compara os indivíduos pareados com os que não foram, foi o componente responsável por tornar o efeito das características observáveis negativo.

Considerando-se os setores desagregados, apenas o setor público demonstrou efeito positivo das características observáveis, no qual atua no sentido de reduzir a diferença de rendimento entre o retornado não branco e o branco. Observa-se, entretanto, diferencial total negativo de rendimento. Em todos os setores ocorreram efeitos discriminatórios em relação ao migrante de retorno não branco. Os setores público e formal privado demonstraram os maiores efeitos discriminatórios, enquanto o setor informal privado evidenciou o menor efeito.

Por fim, é apresentada a análise dos diferenciais de rendimentos, considerando o tipo de domicílio (rural ou urbano) e o setor de trabalho nordestino para onde o migrante retornou. Analisando-se o diferencial de rendimentos no mercado de trabalho agregado, verifica-se que tanto o efeito das características não observáveis, quanto o efeito das características observáveis ${ }^{8}$ atuam no sentido de aumentar as diferenças de rendimentos entre o migrante que retornou para o meio rural nordestino e o que retornou para o meio urbano. Os três componentes, relacionados ao efeito das características observáveis, atuam no sentido de aumentar o gap entre os indivíduos rurais e urbanos.

Verificando-se os setores desagregados, nota-se que, em todos os setores, existem diferenciais totais de rendimentos e efeito discriminatório em relação ao migrante que retornou para o meio rural, comparado ao retornado urbano. Nos setores informal privado e autônomo informal, os efeitos das características observáveis foram negativos, ao passo que nos setores formal privado e público o

8 O efeito das características observáveis negativo, assim como na decomposição do diferencial de renda por cor, pode ser explicado, pelo menos em parte, devido ao fato de o migrante que retornou para o meio rural ser menos escolarizado que o indivíduo que retornou para a área urbana. 
efeito foi positivo, no entanto não foi considerável o suficiente para anular o efeito discriminatório.

Os resultados obtidos no trabalho, de modo geral, confirmam estudos anteriores, como os de Moraes (2005), Mattos e Machado (2006), Pereira e Oliveira (2016) e Mariano, Costa, Guimarães, Souza (2018). As evidencias mostram que, mesmo considerando-se apenas o grupo de trabalhadores denominados migrantes de retorno nordestino, os resultados evidenciam discriminação de renda por sexo, cor e situação de domicílio. Esperava-se que o setor público discriminasse menos do que o setor privado. Consoante Bartalotti e Leme (2007), as regras de contratação e a isonomia por cargo no setor público tendem a prevenir o trabalhador do efeito da discriminação. O funcionalismo público funciona como refúgio contra a discriminação para negros e mulheres ou outra condição que induza efeito discriminatório.

Uma das possíveis explicações para esse resultado é que outras informações importantes nos diferenciais de rendimentos no setor público não foram consideradas, ou seja, não houve distinção entre as diversas categorias de trabalho. Nesse sentido, para uma análise mais aprofunda, seria preciso subdividir os trabalhadores do setor público em categorias profissionais, ${ }^{9}$ como, por exemplo, profissionais da área da saúde, do judiciário, da educação, entre outras, assim como seria necessário separar os trabalhadores por esfera federal, estadual e municipal. Os resultados obtidos no modelo de Ñopo estão de acordo com as evidências apresentada pela estatística descritiva.

\section{Considerações Finais}

Este trabalho teve como objetivo analisar a existência de discriminação de rendimento do trabalho por sexo, cor e situação de domicílio do migrante de retorno nordestino. A análise considerou quatro setores de atividade na região Nordeste: formal privado, informal privado, público e autônomo informal.

Foram utilizados microdados do Censo Demográfico de 2010 extraídos de IBGE (2010). Para se realizar essa análise, utilizou-se o método não paramétrico de Ñopo (2008). Essa metodologia mostra o diferencial de rendimentos entre grupos considerando características similares entre os indivíduos, ou seja, dentro do suporte comum. O efeito total do diferencial pode ser dividido em efeito das características observáveis e efeito discriminatório.

Os dados da estatística descritiva revelaram que o migrante de retorno nordestino que trabalha no setor público, comparado aos indivíduos dos demais setores, apresentou os maiores anos de estudos, maiores níveis de rendas e menores

9 Analisar o diferencial de rendimento no setor público por categoria profissional foge aos objetivos deste trabalho. Essa hipótese levantada fica como sugestão para pesquisas futuras. 
horas trabalhadas semanalmente. Os indivíduos do sexo masculino apresentaram maiores rendimentos e trabalharam mais horas semanalmente em todos os setores, entretanto são menos escolarizados que as mulheres. As pessoas que retornaram para o meio urbano e os retornados com cor branca, de modo geral, formam mais bem remunerados.

Com base na decomposição de Ñopo, observou-se no mercado de trabalho agrupado a existência de um diferencial total de renda para o migrante de retorno mulher $(-0,0714)$, em relação ao homem. O efeito das características não observáveis foi de $-0,0834$, sendo que o efeito das características observáveis atua no sentido de reduzir o diferencial de rendimento. Considerando-se o mercado de trabalho desagregado, verificou-se que todos os setores de atividades evidenciaram efeitos discriminatórios em relação às mulheres. Nos setores informal privado e público, o efeito das características observáveis age no sentido de aumentar o diferencial de rendimentos.

A análise por cor no mercado de trabalho agregado apresentou diferencial de renda $(-0,0587)$ sobre o retornado não branco devido tanto ao efeito das características observáveis quanto ao das características não observáveis. Considerando-se os setores desagregados, assim como na análise por sexo, o efeito discriminatório por cor foi evidenciado em todos os setores. Em relação ao efeito das características observáveis, os quatro setores denotaram efeitos negativos em relação aos não brancos. O menor efeito não observável ocorreu no setor informal privado, seguido do setor autônomo informal.

Por fim, foram mostrados os resultados da decomposição do diferencial de rendimento por situação de domicílio (rural ou urbano). Os resultados tiveram efeitos das características não observáveis negativos, tanto no mercado de trabalho agregado quanto por setores, de modo a beneficiar o retornado urbano. No setor público, tanto o diferencial total de rendimento quanto o efeito discriminatório foram maiores do que nos demais setores. Com relação ao efeito discriminatório no setor público, esperava-se que fosse baixo ou praticamente inexistente.

Pode-se concluir, de acordo com a base de dados utilizada nesta pesquisa, que os resultados referentes ao diferencial de rendimento do migrante de retorno nordestino mostram-se relevantes, visto que tanto o efeito das características observáveis quanto o efeito das características não observáveis impactam na renda dos indivíduos. Além disso, esses efeitos oscilam dependendo do setor de trabalho e das características dos retornados. Isso reforça a literatura quanto à importância dada às políticas públicas na redução da discriminação de renda entre os trabalhadores com características produtivas similares. 


\section{Referências}

ABRAMO, L. Desigualdades de gênero e cor no mercado de trabalho brasileiro. Ciência e Cultura, v. 58, n. 4, 2006.

ALMEIDA, A. T. C.; ARAUJO JUNIOR, I. T. Diferenciais compensatórios de salário para trabalhadores com preferências heterogêneas: evidências para o caso brasileiro. In: ENCONTRO REGIONAL DE ECONOMIA, 22., 2017, Fortaleza. Anais eletrônicos [...]. Fortaleza: ANPEC, 2017.

ARAÚJO, T. B. Industrialização do nordeste: intenções e resultados. In: ENSAIOS sobre o desenvolvimento brasileiro: heranças e urgências. Rio de Janeiro: Revan, 2000, p. 143-154.

BANCO DO NORDESTE BRASILEIRO. BNB. Quadro macroeconômico Brasil e Nordeste 2000 a 2010. 2012. Disponível em:

https://www.bnb.gov.br/documents/88765/89729/indicadores_macroeconomicos_brasil_ nordeste_fev12.pdf/d6a134e4-99c0-472f-a244-d771397550c5. Ācesso em: 27 de nov. 2018.

BARTALOTTI, O.; LEME, M. C. S. Discriminação salarial além da média: uma abordagem de decomposição contrafactual utilizando regressões. In: ENCONTRO NACIONAL DE ECONOMIA, 35., 2007, Recife. Anais eletrônicos [...] Recife: ANPEC, 2007. v. 1, p. 1-19.

BRITTO, A. M.; WALTENBERG, F.D. É atrativo tornar-se professor do ensino médio no Brasil? Evidências com base em decomposições paramétricas e não paramétricas. Estudos Econômicos, v. 44, n.1, p. 5-44, 2014.

BLINDER, A. S. Wage discrimination: reduced form and structural estimates. Journal of Human Resources, v. 8, n. 4, p. 436-455, 1973.

CUNHA, A. S. Migração de retorno num contexto de crises, mudanças e novos desafios. In: ENCONTRO ABEP - ASSOCIAÇÃO BRASILEIRA DE ESTUDOS POPULACIONAIS, 12. 2000, Caxambu. Anais eletrônicos [...]. Caxambu: ABEP 2000.

CUNHA, J. M. P. A migração no começo do século 21: continuidades e novidades trazidas pela PNAD 2004. Parcerias Estratégicas, v. 22, p. 381-439, 2006.

CUNHA. J.M.; BAENINGER, R. A migração nos estados brasileiros, no período recente: principais tendências e mudança. In: ENCONTRO NACIONAL SOBRE MIGRAÇÃO, 2., 2000, Belo Horizonte. Anais eletrônicos [...]. Belo Horizonte: ABEP, 2000. p. 117-165.

DUSTMANN, C.; KIRCHKAMP, O. The optimal migration duration and activity choice after re-migration. Journal of Development Economics, v. 67, p. 351-372, 2002.

FERNANDES, R. Desigualdade salarial: aspectos teóricos. In: CORSEUIL, C. H.; FERNANDES, R.; MENEZES FILHO, N.; COELHO, A. M.; SANTOS, D. D. Estrutura salarial: aspectos conceituais e novos resultados para o Brasil. Rio de Janeiro: IPEA, 2002.

GUIMARAES NETO, L. Mercado de trabalho no Nordeste: 2000-2010: avanços e desafios. Recife, 2012. Disponível em: https://web.bndes.gov.br/bib/jspui/bitstream/1408/5250/1/ Mercado\%20de\%20trabalho\%20no\%20Nordeste_15_P_BD.pdf. Acesso em: 20 de jan. 2017. 
IBGE-INSTITUTO BRASILEIRO DE GEOGRAFIA E ESTATÍSTICA. Microdados do censo demográfico de 2010. 2010. CD-ROM.

IBGE. Pesquisa nacional por amostra de domicílios de 2014. Rio de Janeiro, 2014. Disponível em: <https:/www.ibge.gov.br/estatisticas/sociais/populacao/9127-pesquisa-nacional-poramostra-de-domicilios.html? =E्Et=downloads > . Acesso em: 28 de nov. 2019.

JUSTO, W. R.; SILVEIRA NETO, R. M. Migração e seleção: evidências para o Brasil. In: ENCONTRO NACIONAL DA ASSOCIAÇÃO BRASILEIRA DE ESTUDOS REGIONAIS E URBANOS, 5., 2007, Recife. Anais eletrônicos [...]. Recife: ABER, 2007.

LIMA, A. C. C.: SIMÕES, R.; OliVEIRA, A. M. H. C. Caracterização dos padrões migratórios brasileiros no período 1980-2010. In: ENCONTRO NACIONAL DE ESTUDOS POPULACIONAIS, 18., 2012, Águas de Lindóia-SP. Anais eletrônicos [...] Águas de LindóiaSP: ABEP 2012.

LIMA, C. F.; JUSTO, W. R. Perfil do migrante de retorno nordestino: evidências econométricas com base no censo de 2010. In: ENCONTRO PERNAMBUCANO DE ECONOMIA POLÍTICAS PARA O DESENVOLVIMENTO ESTADUAL, 3., 2014, Recife. Anais eletrônicos [...]. Recife: ENPECON,2014.

MATTOS, R. S.; MACHADO, A. F. Diferencial de rendimentos por cor e sexo no Brasil (19872001). Econômica, v. 8, n. 1, p. 5-27, 2006.

MACHADO, A. F. OLIVEIRA; A. M. H. C.; ANTIGO, M. Evolução do diferencial de rendimentos entre setor formal e informal no Brasil: o papel das características não observadas. Revista Economia Contemporânea, v. 12, n. 2, p. 355-388, 2008.

MARIANO, F. Z.; COSTA, E. M.; GUIMARÃES, D. B.; SOUZA, D.T. Diferenciais de rendimentos entre cors e gêneros, nas regiões metropolitanas, por níveis ocupacionais: uma análise através do pareamento de Ñopo. Estudos Econômicos, v. 48, n. 1, p. 137-173, 2018.

MORAES, S. M. A. Discriminação salarial por gênero nos segmentos industriais do Brasil: uma análise para os anos de 1993, 1998 e 2003. 2005, 115 f. Dissertação (Mestrado em Desenvolvimento Econômico) - Universidade Federal do Paraná, Curitiba, 2005.

ÑOPO, H. Matching as a tool to decompose wage gaps. The Review of Economics and Statistics, v. 90, n. 2, p. 290-299, 2008.

OAXACA, R. L. Male-female wage differentials in urban labor markets. International Economic Review, v. 14, p. 693-709. 1973.

OLIVEIRA, K. F; JANNUZZI, P. M. Motivos para migração no Brasil e retorno ao Nordeste: padrões etários, por sexo e origem/destino. São Paulo em Perspectiva, v. 19, n. 4, 2005.

PEREIRA, R. M.; OLIVEIRA, C. A. Os diferenciais de rendimento por gênero no Rio Grande do Sul: uma aplicação do modelo de Heckman e da decomposição de Oaxaca-Blinder. Redes, v. 21, p. 148-173, 2016.

RAMALHO, H. M. B.; SILVEIRA NETO, R. M.: Migração de retorno e escolha ocupacional no Brasil. In: ENCONTRO NACIONAL DA ASSOCIAÇÃO BRASILEIRA DE ESTUDOS REGIONAIS E URBANOS, 7., 2009, São Paulo. Anais eletrônicos [...]. São Paulo: ABER, 2009. 
SANTOS, W. B.; RAMALHO, H. M. B. Diferenciação salarial entre os emigrantes rurais da Paraíba e os nativos urbanos brasileiros. Economia e Desenvolvimento, v. 10, p. 55-89, 2011.

SILVEIRA NETO, R. M.; AZZONI, C. R. Non-spatial public policies and regional inequality in Brazil. In: RSAI WORLD CONGRESS, 2008, São Paulo. Anais eletrônicos [...]. São Paulo: NEREUS, 2008.

SIQUEIRA, L. B. O.; MAGAlHÃES, A. M.; SILVEIRA NETO, R. M. Uma análise da migração de retorno no Brasil: perfil do migrante de retorno, a partir do censo de 2000. In: ENCONTRO REGIONAL DE ECONOMIA, 11., 2006, Fortaleza. Anais eletrônicos [...]. Fortaleza: [s. n.], 2006.

SIQUEIRA, L. B. O.; MAGALHÃES, A. M.; SILVEIRA NETO, R. M. Perfil do migrante de retorno no Brasil: evidências a partir do Censo de 2000. In: ENCONTRO NACIONAL DE ESTUDOS POPULACIONAIS, 16, 2008, Caxambú. Anais eletrônicos [...]. Caxambú: ABEP, 2008.

THOMAS, V.; WANG, Y.; FAN, X. Measuring education inequality: Gini coefficients of education measuring education inequality. The World Bank, p. 1-37, 2000.

\section{Apêndice A}

Tabela 4 - Características do migrante de retorno nordestino por setor de trabalho

\begin{tabular}{ll|c|c|c|c}
\hline \multirow{2}{*}{} & Variáveis & \multicolumn{2}{|c|}{ Setor formal } & \multicolumn{2}{c}{ Setor informal } \\
\cline { 3 - 6 } & $\begin{array}{c}\text { Setor } \\
\text { formal } \\
\text { privado } \\
\text { (\%) }\end{array}$ & $\begin{array}{c}\text { Setor } \\
\text { público } \\
\text { (\%) }\end{array}$ & $\begin{array}{c}\text { Setor } \\
\text { informal } \\
\text { privado } \\
\text { (\%) }\end{array}$ & $\begin{array}{c}\text { Setor } \\
\text { autônomo } \\
\text { informal } \\
\text { (\%) }\end{array}$ \\
\hline Sexo & Homem & 64,38 & 31,50 & 58,51 & 73,85 \\
& Mulher & 35,62 & 68,50 & 41,49 & 26,15 \\
\hline Cor & Branco & 62,65 & 60,79 & 59,36 & 59,79 \\
& Não branco & 37,35 & 39,21 & 40,64 & 40,21 \\
\hline Estado civil & Solteiro & 87,58 & 90,73 & 83,98 & 73,73 \\
& Nũo solteiro & 12,42 & 9,27 & 16,02 & 26,27 \\
\hline \multirow{2}{*}{ Instrução } & Fundamental incompleto & 40,28 & 40,25 & 58,54 & 58,40 \\
& Fundamental completo & 16,68 & 7,25 & 20,28 & 20,55 \\
& Médio completo & 26,33 & 33,00 & 24,69 & 23,16 \\
& Superior completo & 32,34 & 55,25 & 13,47 & 5,92 \\
\hline
\end{tabular}

Fonte: Elaboração própria a partir de IBGE (2010). 
Tabela 5 - Média de idade, renda e horas trabalhadas do migrante de retorno nordestino: análise por setor de trabalho

\begin{tabular}{|c|c|c|c|c|c|c|c|c|}
\hline \multirow[t]{2}{*}{ Variáveis } & \multicolumn{2}{|c|}{$\begin{array}{l}\text { Setor formal } \\
\text { privado }\end{array}$} & \multicolumn{2}{|c|}{ Setor público } & \multicolumn{2}{|c|}{$\begin{array}{l}\text { Setor informal } \\
\text { privado }\end{array}$} & \multicolumn{2}{|c|}{$\begin{array}{c}\text { Setor autônomo } \\
\text { informal }\end{array}$} \\
\hline & Média & $\begin{array}{l}\text { Desvio } \\
\text { padrão }\end{array}$ & Média & $\begin{array}{l}\text { Desvio } \\
\text { padrão }\end{array}$ & Média & $\begin{array}{l}\text { Desvio } \\
\text { padrão }\end{array}$ & Média & $\begin{array}{l}\text { Desvio } \\
\text { padrão }\end{array}$ \\
\hline Idade & 37 & 9.73 & 38 & 9.62 & 34 & 9.30 & 36 & 8.30 \\
\hline $\begin{array}{l}\text { Anos de } \\
\text { estudos }\end{array}$ & 11 & 4.88 & 14 & 3.34 & 8 & 4.22 & 7 & 3.53 \\
\hline Renda & 1508 & 1562.58 & 2240 & 2475.39 & 745 & 1014.78 & 700 & 796.69 \\
\hline $\begin{array}{l}\text { Horas tra- } \\
\text { balhadas }\end{array}$ & 40 & 16.48 & 31 & 9.94 & 36 & 19.99 & 41 & 22.82 \\
\hline
\end{tabular}

Fonte: Elaboração própria a partir de IBGE (2010).

Nota: Renda $=$ renda mensal do trabalho principal; as horas trabalhadas são semanalmente. 


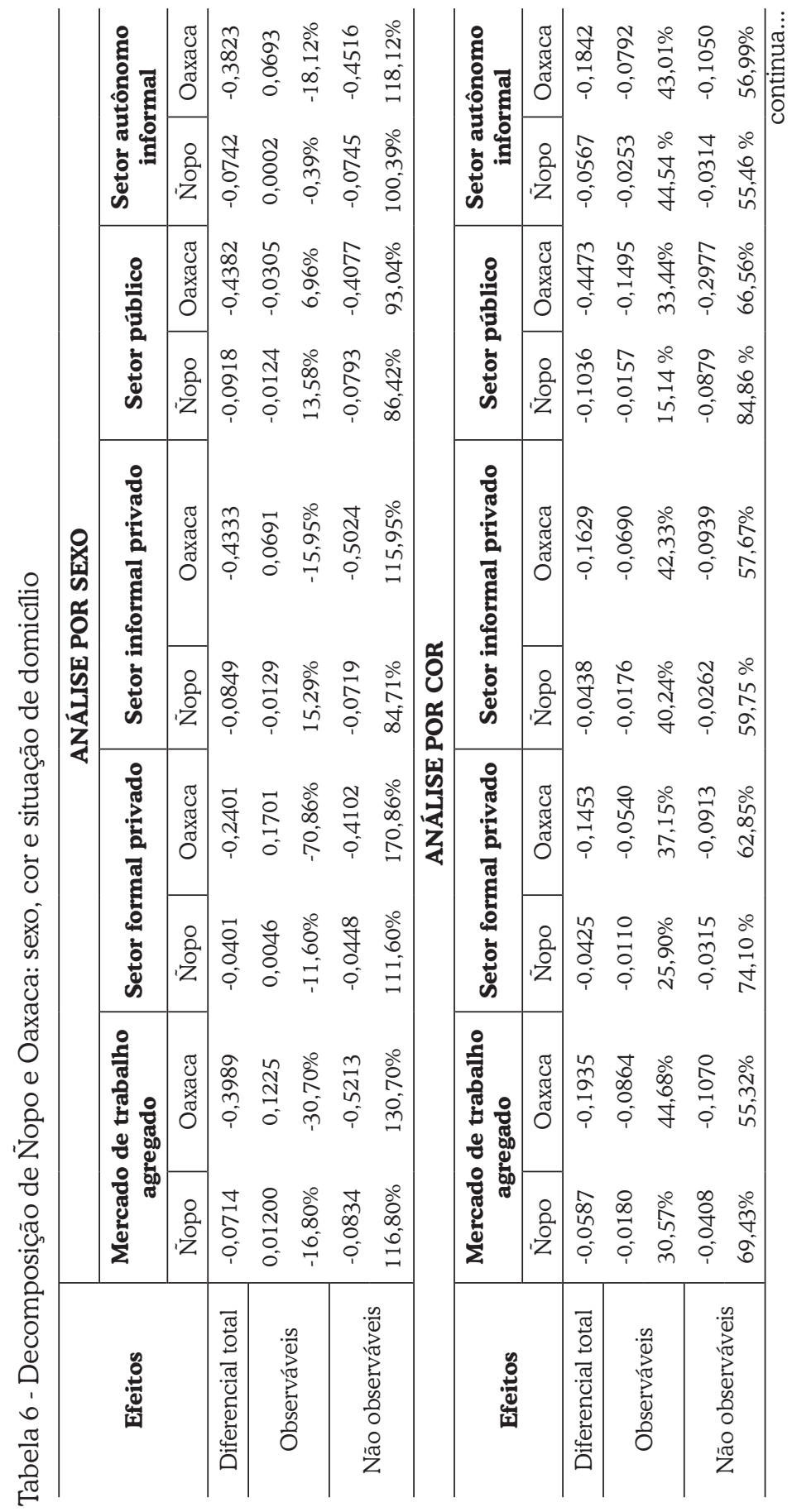

Análise Econômica, Porto Alegre, v. 38, n. 75, p. 131-158, mar. 2020. 


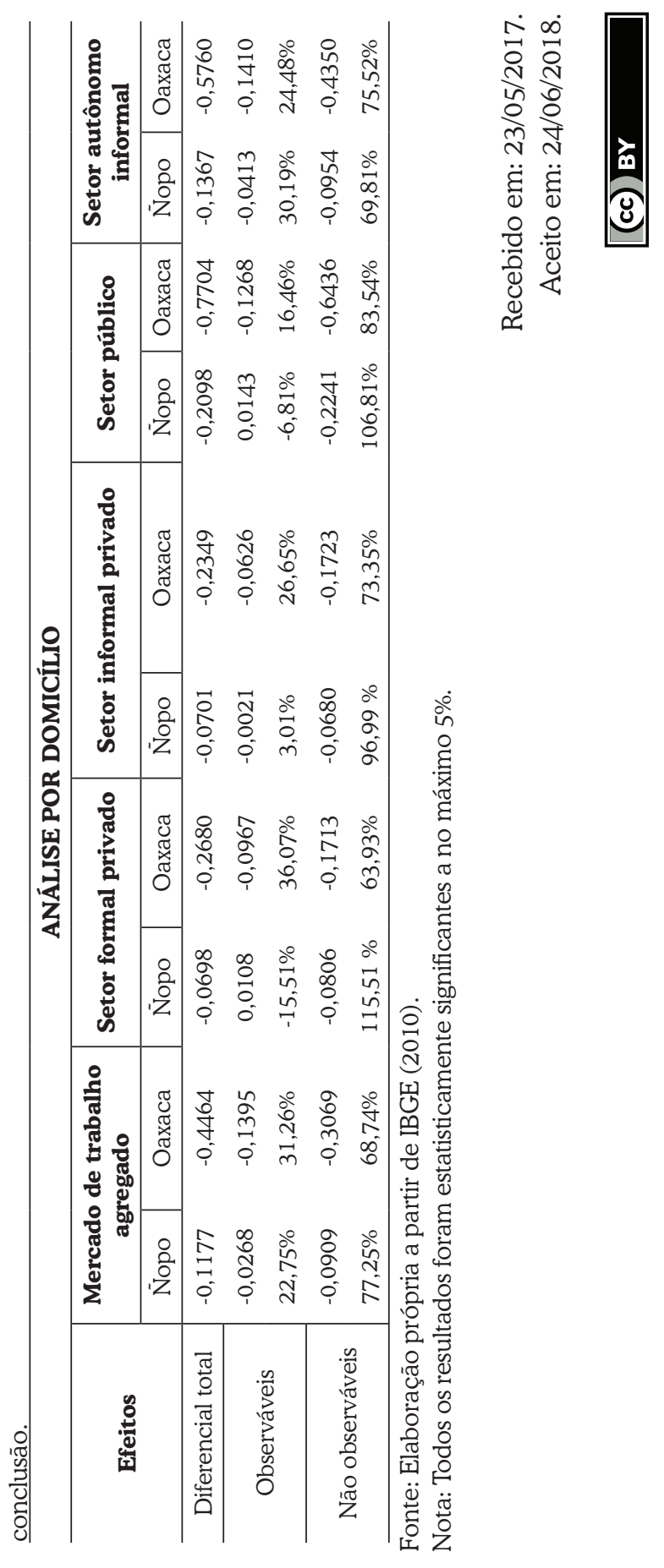

